\title{
FROM APPFEST TO ENTREPRENEURS: USING A HACKATHON EVENT TO SEED A UNIVERSITY STUDENT- LED ENTERPRISE
}

\author{
David Cobham ${ }^{1}$, Carl Gowen ${ }^{2}$, Kevin Jacques ${ }^{1}$, Jack Laurel${ }^{2}$, Scott Ringham ${ }^{2}$ \\ University of Lincoln, UK: academic member of staff \\ University of Lincoln, UK: undergraduate student
}

Keywords: Hackathon, entrepreneur, student enterprise, and university-led business.

\begin{abstract}
Hackathons were once industry-specific programming sprints to get overdue features and applications completed; today they are a worldwide phenomenon, with businesses, educators, and entrepreneurs taking an interest in the benefits they can provide. Hackathons can be a breeding ground for brainstorming, innovation, networking, and product development, and as such they can have multiple outcomes including the sparking of new businesses and entrepreneurial activity. This paper investigates the effectiveness of utilising a hackathon as the genesis for the creation of sustainable student entrepreneurial activity. In particular, it seeks to evaluate the effectiveness of using hackathon-type events to initiate a successful University student enterprise project. The paper outlines the findings from this project, and concludes with a series of recommendations from the authors, on how one should market and structure a hackathon, and whether this vehicle should be chosen as a means to initiate a student enterprise project.
\end{abstract}

The key factors that led to the success of this project were: the degree of formal structure that was introduced into the timings of the principle activities, not normally a feature of this kind of event, including scheduled "diversions" to break up the weekend; keeping the goals achievable; the duration of the event, in this case 48 hours spread over three days; the involvement of representatives from local businesses in the judging process; and crucially the adoption of an over-riding ethos for the event that focussed not on providing completed problem solutions but on potential innovative solutions that may not have been fully-functional.

Areas for improvement included: inviting more students from earlier study years of degree programmes, not always the target audience for University hackathon activity; inviting students from a wide range of disciplines to ensure a broad set of participant skills and to encourage the formation of multi-disciplinary groupings by enforcing a balance of skills across teams, which as a corollary means not always allowing friendship groups to remain together; employing a team sufficiently large enough to support the duration of a long event; and careful consideration of the extent of competitiveness adopted in the event ethos.

The project was part of the institution's "Student as Producer" initiative where students and staff work side-by-side on research projects. Undergraduate students were fully involved in all aspects of the project, including an independent team who contributed to the authoring of this paper.

\section{INTRODUCTION}

Many Universities have taken a keen interest in the development of entrepreneurial skills in their students [1] [2] [3]. This has been seen to be an important area of graduate skills development, and is purported to better prepare students after graduation for the world of work [4]. A particular instance of the development of entrepreneurialism can be seen in the creation of University student enterprises [1] [5]. These are often internally-hosted businesses, run by students sometimes with support from staff, that can trade and function in a relatively safe and low-risk environment. The University of Lincoln hosted a three-day hackathon-inspired event, called 'AppFest', with the intention of producing an environment and climate that would lead to the creation of a student enterprise. From the hackathon, a sub-set of students would take the ideas and foundations from AppFest and develop them further, with support from the university, into a new start-up business. The nature of the business would be an app/web site development company. 
This paper aims to assess the effectiveness of using a hackathon event in order to initiate a start-up company. The success of the student enterprise itself will be considered in future research.

\section{METHODOLOGY}

A case study approach was chosen to conduct research into the success of the project. A set of criteria were drawn up to evaluate the successfulness of the approach adopted, and to provide a framework for making suggestions for similar future projects.

To support and further validate this approach, interviews and survey questionnaires [6] [7] were conducted. Both methods were used for gathering data from the students involved in the AppFest hackathon, and from university staff involved in running and organising both the hackathon and the enterprise extension project. The data gathered includes both quantitative and qualitative results which were combined with secondary research to attempt to evaluate the effectiveness of the project.

\section{LITERATURE REVIEW}

A number of approaches to developing student enterprises have been previously trialled, including cross-institution competitions, insight courses, and virtual business activities [8]. Hackathons have also been investigated as a foundation for start-ups [9].

Hackathons are generally conducted as events in which participants gather in a single location, where a challenge or theme is proposed, and operate over a short, fixed period of time (such as a day or a weekend). Participants form small groups and develop software prototypes, often concluding with presentations from each team [9] [10] [11]. The name 'hackathon' is a combination of 'hack' and 'marathon' and has no reference to the computer-related crime of hacking [12] [13]. Hackathon events are often called things with postfixes such as "-fest" or "-jam" or "-camp" - e.g. codefest, gamejam, Robo-camp [11] [14]. Most hackathons focus on software development and most participants have software-related backgrounds or qualifications [13]. However, there are hackathons that focus on hardware too; such hackathons often make use of 'hackerspaces' which contain the equipment required for developing hardware products [14]. Hackathons sometimes include a contest or competitive element, and prizes can often be monetary or support for further development [13] [14]. However, hackathons focused on open source projects often do not include competition [14].

Hackathons have quickly grown in popularity and they have diversified from the software development house environment prevalent in their early incarnations [14]. There are many examples of hackathons being hosted by social media companies like Facebook and Twitter [15], in anti-malware developers like F-secure [11], and even in British Airways [16]. The characteristics of the participants has also broadened, with the numbers of non-technical experts increasing with the popularity of hackathons [14]. This provides an opportunity for networking outside of existing groups of experts and developers [13], which potentially provides a fertile ground for start-ups since networking is widely recognized as important to successful entrepreneurship [17] [18] [19].

Research conducted by Mumm [20] into the demographics of 'hackers' queried 150 hackathon attendees, hosts, and sponsors. Responses indicated that only $11 \%$ of attendees are female, only $18 \%$ of attendees are more than 34 years old, $77 \%$ described themselves as developers, and $70 \%$ attended previous hackathons. The same survey also found that the two most common reasons why people attend hackathons are learning (85\%) and networking (81\%).

Regardless of the opportunities and benefits in staging hackathons, it is generally recognised that it is important not to host hackathons too frequently where the potential population of participants is limited as this could result in creative fatigue [14].

The additional opportunity to exploit the entrepreneurial potential of hackathons was identified by Delhi [9], who proposed that in the hackathon that formed the basis of his case study three teams involved all did "extensive development" but that they had also developed networks through the hackathon that afforded them the resources and expertise required to develop products, and concluded that they could 
effectively be characterised as business start-ups, evidencing the potential to create enterprises from Hackathons.

\section{THE EVENT: APPFEST}

The AppFest event took place in the University of Lincoln computing labs from 16-18 October 2015. The event was advertised as a 48-hour app creation marathon where students would try to design and prototype an application to provide support for an upcoming university open day. The client for the app was the University marketing department. The main advertised goal of the AppFest was to try to get creative thinkers, designers and coders to come together and pitch ideas to a panel on how they believed that the open day app should be best implemented. It was heavily implied throughout the event that the focus was on the design and not making the final product. During the 48 hours there were many breaks scheduled and diversionary activities encouraged in order to promote socialisation as well as refreshment. Twenty-two students attended the event from a range of subject disciplines. About onethird of the participants came from a design background with the majority studying a programme from the School of Computer Science. Students were initially unaware that the secondary goal of running this AppFest was to lead to the development of a small company or business. It was felt that making this additional future intention explicit from the outset might affect the behaviour of the participants in an unhelpful way, possibly stifling some of the more creative elements of the event. A competitive element was introduced by promoting that there would be prizes for what was judged to be the best work produced.

At the end of the final day of AppFest, teams presented their achievements to a panel of academic and professional support staff and local employers. Each team brought something different to the table and all participants won an award in some form. After the event, teams were invited to a follow up event to discuss forming a student enterprise which as its first commission would take forward the open day application. Any participant from the AppFest event who expressed an interest was invited to join the secondary student enterprise phase irrespective of their performance level in the initial competition.

\section{ANALYSIS}

\section{Team Members Interview}

Participants identified that the primary reason cited for attending the AppFest was that the event would give them something enjoyable to do whilst also providing a CV enhancement which would increase their future employability. Many stated that they attended to try to get the most out of their university experience.

The participants were generally happy with the event and how much they had achieved. There appeared to be agreement that it was a great opportunity and it was considered to be very useful for their individual futures and career development. The inclusion of employer participation in the event was thought be very beneficial.

The 48-hour time scale of the event was unanimously praised. Many of the team members have previously been part of 24-hour events and stated that these events were too gruelling and tiring, leading to the production of low quality work. A 48-hour event that allowed for periods of rest and recuperation was cited as a significant improvement over the intensive 24-hour version. The group believed that the initial AppFest event was one of the best that had been hosted at the University, praising the quality of its organisation. Reflecting on the nature of hackathon events, the group believed that they should be in a competitive yet relaxed environment. They expressed a view that in events like this, participants should be allowed to be with their friends; when asked if the group would be interested in taking part in a hackathon where they were put randomly into a team, some seemed heavily disheartened by the idea stating that being able to work with friends is crucial and that they would refuse to work if they couldn't be with their friends.

Comments were made that the hackathon was a great way to get people hooked into development, however it was disappointing that there were very few first year/low experience attendees. The group believed this is because students at earlier stages in their educational programme feel like they are not 
yet at the standard of technical capability that a hackathon might require, whereas in reality even the main group recognised that they didn't possess all of the skills required to produce the application in this event at the outset. The group felt it would be good if somehow the event could be opened up more towards earlier stage students, such as having first year-only events to try to boost their confidence or by having events where third or fourth year students would volunteer to act as a champion to those at earlier stages.

The group felt strongly that hackathon events like this need to be opened up to other disciplines; it was thought that currently they are heavily geared towards computer science students with few from other areas of study. An event of this style should be advertised more heavily to art, business, drama and other students, particularly as the AppFest event was about creativity, not coding capability. The group further said that it would have been very useful if more students with graphic design skills were included as none of the current group feels strong in graphical capabilities. A team of 'pure coders' was less well placed to approach general design and user interfaces. During the development of the project some students left the team; this was believed to be as a result of feeling incapable and of being a liability to the team. Others also left as they were not strong in programming.

The group felt that if the advertising for the event had made it clearer that it would lead to future opportunities, such as the student enterprise, then more people would probably have taken part.

Some group members had previously spoken about forming a business, but had never 'got the ball rolling', and as a result were very grateful for the university for allowing them to build an enterprise that would benefit from a great deal of institutional support.

\section{Hackathon Coordinator Interview}

The Coordinator of the hackathon event was positive about the AppFest; among other things he was pleased with the attendance, the groups' unique contributions, and resources made available to the hackathon. He stated the event was a pilot project intended to utilise students' creativity to start an enterprise. Originally the 'winning' group from the hackathon was to be selected to start an enterprise based upon their idea, however the enterprise opportunity was ultimately made openly available to all participants, in order to preserve the best of the ideas and to give the enterprise a broad membership.

The event coordinator was pleased with the 48-hours given for the event. The event format, with students going home at the end of each day, was a structure which he believed kept participants creative and energised throughout the event. In the same vein, regular breaks, socialisation, and recreational activities (such as gaming on provided consoles) were encouraged to maintain a relaxed atmosphere with food and drinks provided. Having a creative environment was an objective of the event, something which he believed was achieved, however it was noted that computer students were particularly competitive.

The resources made available to the event - the location, the staff, and equipment - were considered very good, and when asked, the organiser could not think of any additional resources which he would have liked to see.

While he was pleased with the participation, a more balanced mix of technical students and design students had originally been sought. In the turnout for the event, only one third of students came from a design background, which he considered to be unfortunate. This problem was compounded by members only seeking to work with and form groups with their existing friends, who often studied the same course. Consequently, the event coordinator stated a desire for greater participant skill set diversity, and when queried on whether he would like to see participants assigned into balanced groups in future hackathons, responded positively, adding that participants should embrace the element of working with strangers as it reflects the world of employment. Unlike the response of the participants, he expressed satisfaction with the balance of attendance of students in early and later stages of their studies.

As the goal of the hackathon was to produce an enterprise, it was posited during interview that including students from business courses after the initial hackathon phase would help stimulate the transformation to enterprise. The organiser responded to this suggestion by saying it could potentially do more harm 
than good, as team members may resent those who haven't done as much work as others, and therefore forcing students into the mix could result in animosity and reduced enthusiasm for the project.

The AppFest was never meant to be about the final app, rather about the design and foundations of a potentially successful app. As a consequence, the coordinator tried to ensure students were not distracted by unachievable goals. Furthermore, he claimed that the simplest apps (referencing Flappy Bird and Pokemon Go) are often the most successful, and therefore over-complication should be avoided. However, students were encouraged to work outside of their comfort zone and try new or difficult things.

The coordinator considered the event beneficial in many ways - the event provided attendees with a networking opportunity to meet new people, as well as a great way to demonstrate willingness and selfmotivation which could then feature on their $\mathrm{CV}$. He further stated that future hackathons should be run by multiple coordinators, stating that acting as the sole organiser was very difficult and tiring. He also expressed interest in student-led hackathons which would provide the student organisers with additional experience and enhancement for their CV.

The event concluded with presentations before a panel made up of academics from various schools in the university, the marketing department (the client), and representatives of local businesses including a local major on-line banking business. The panel had a great deal of praise for the work undertaken during the AppFest. The coordinator considered many students were nervous during the presentation, adding that they didn't convey themselves well, and that some presentations seemed over-rehearsed and could have been more inspiring. He suggested that drama students (despite their lack of technical knowledge) may be worth including in participant teams simply because of their higher levels of presentation skills.

\section{SUMMARY OF FINDINGS}

The AppFest event's main goal was to produce a student-led enterprise; that goal was accomplished, and the team members and staff involved were largely satisfied by the outcome of the event, with one development team member claiming that the AppFest event was one of the best that had ever been hosted at the University. Although the organisation of the hackathon was received very well, the sole coordinator felt that future events should have multiple organisers given the complexity and intensity involved in its implementation. The venue and resources available for the event's attendees were well received, with the 48-hour timeframe given to the project being highly praised. In particular, both the development team and the event coordinator felt that the timeframe gave them opportunities to rest and relax between days, whilst still having enough time to develop ideas to a good level of detail. There was, however, disagreement about the optimal atmosphere for a hackathon event. Team members, many of whom were veterans of many previous hackathons, preferred an atmosphere of social relaxation and friendliness. In a competitive environment, they believed that the sharing of knowledge or work between teams is invariably shunned. Whilst the hackathon organiser was not hostile to the notion of competitive hackathons, he felt that creativity provides the optimal atmosphere. When queried on their views of hackathon atmospheres, creativity was not mentioned by the other interview sources.

There was a consensus that the hackathon event could have been better promoted, partly because of the lack of diversity of skills among participants. Most students came from a computer science background and all interviewees lamented the lack of students from a design and business background. Because of the nature of the AppFest task, Design students in particular were sought after by the technical team members who struggled to approach the many facets of developing user interfaces and graphical implementation of marketable applications.

The project's ultimate goal of producing a business was hidden from participants which inevitably led to a lack of students with business skills applying for the AppFest event. There was consensus that should one wish to encourage students from business and design disciplines to participate, then the eventual goal should have been made clear and promoted to students from those respective schools across the university. It was also noted that the atmosphere of hackathons may be off-putting to students from disciplines other than computer science and that further work needed to be done to make the event attractive to those students from non-technical backgrounds. 
It was posited that many of those involved in the hackathon wanted to work only in friendship groups; to form groups that had a broader range of skills, such as design and business knowledge, would require breaking this preference. When this suggestion was put to participants they reacted very negatively, stating that working with friends was crucial, and that they might refuse to attend if denied the ability to work with friends. The AppFest organiser was markedly more receptive to the idea, commenting that such an approach reflects the world of employment, and would therefore provide additional benefits to attendees.

Aside from the actual production of a student enterprise, hackathon events like AppFest benefit attendees in multiple other ways. The team members were united in the view that the hackathon could get programmers and designers enthused into developing digital solutions, potentially inspiring them to produce great work. This was echoed by the coordinator, who considered the event as a tool for students to network with others. He encouraged the event's attendees to leave their comfort zone and try to attempt things even if they had little prior experience. He also added it would demonstrate their selfmotivation - an attractive trait to have evidenced in their CVs. Furthermore, he stated that AppFest was not orientated around the final product, but instead toward the foundations of potentially successful enterprise and long term application development. He stressed that he tried push the same notions (without revealing the goal of the event) to the students, and attempted to focus the students away from unachievable and unrealistic goals. He added that students should actually avoid over-complicating their projects in general since, in his view, simple apps are often the most successful. The organiser also commented on the students' performance in the final presentations of the event; he considered them nervous, poorly conveyed, and over-rehearsed, and suggested that drama students would make useful team members here, not least for aiding with their presentation skills.

\section{EVALUATION FRAMEWORK}

Based on a review of the research carried out the following "good-practice" features have been extracted. The authors recommend that any future hackathon event aiming to generate a student enterprise should follow these guidelines:

- The event needs to be well-planned and well-organised, possibly more so than traditional hackathons whose success derives largely from informality.

- There should be multiple leaders/coordinators who can provide ongoing support throughout the actual hackathon event.

- The venue and resources should be selected to provide a high quality, business-like environment.

- The event should have a sufficiently long timeframe with adequate breaks between periods of activity rather than the more common 24-hour, non-stop hacking format. The AppFest format of 48 hours over 3 days, was extremely well received by the participants and is recommended as a good pattern to follow.

- A wide variety of participant skillsets and contributing subject areas should be targeted in advertising the event. Furthermore, the event's purpose (to establish a business) should be very clearly advertised if an objective is to entice students who would not usually attend hackathons (such as non-computer science students).

- Early decisions need to be made about the optimal atmosphere for a particular hackathon event. The event can be conducted in an atmosphere of social relaxation and friendliness, or with competitive nature, but it seems both competitive and relaxed in a single event is seen to be unachievable. The sharing of ideas is more likely to come about in the former which is useful if it is planned to open up involvement in student enterprise. Alternatively, if it is decided at the outset to only involve the winning group to proceed to form the enterprise a more competitive atmosphere may have greater benefits

- Decisions need to be taken as to whether groups are formed randomly or self-selected. The former is more likely to help foster a business-like atmosphere which is more conducive to the goal of 
creating a student enterprise; the latter is more likely to attract a larger number of participants who might enjoy and therefore engage more with the hackathon event.

- Integration of different student skillsets should be carried out during the team-formation stage of the event. Groups attending hackathons often work in closed groups of friends, who tended to come from the same subject background. For hackathons that are more entertainment-based this might be an ideal format, but for an event with a more business focus, this is less useful.

\section{CONCLUSION}

The device of using a hackathon to generate a student enterprise appears to have worked well. Student participation in the event was good with high levels of enjoyment and good results produced. Students engaged fully with the AppFest element and a good proportion of those participants went on to form the student business. The beneficial outcomes of participating in a hackathon such as the bonding between participants, the development of fresh ideas, the working as a team to solve a collective problem, all assisted in the successful forming of a student enterprise. The management of the event intentionally took a more structured and directed form than would normally be the case at other hackathon events. This direction helped to provide a framework for transferring from a looser form of activity to a more business-like form of engagement in a commercial setting.

Future research is now being undertaken to investigate the success of the student enterprise and to investigate how much of that success can be attributed to the initial start-up via the hackathon route.

\section{ACKNOWLEDGEMENTS}

The research carried out and the resulting paper were conducted under the institution's "Student as Producer" initiative where all students, including undergraduates, are encouraged to engage with the principles and practice of research. The authors would like to thank the institution for providing the funding which has enabled this activity to come to fruition.

\section{REFERENCES}

[1] Duval-Couetil, N., Shartrand, A. and Reed, T. (2016) The role of entrepreneurship program models and experiential activities on engineering student outcomes. Advances In Engineering Education, 5(1) 1-27.

[2] Rasmussen, E., Benneworth, P. and Gulbrandsen, M. (2015) How academic entrepreneurship meets the university: university spin-offs in stakeholder network. Available from http://doc.utwente.nl/97965/ [accessed 29 July 2016]

[3] Mars, M.M., Slaughter, S. and Rhoades, G. (2008) The state-sponsored student entrepreneur. The Journal of Higher Education, 79(6) 638-670.

[4] Burniston, S., Rodger, J. and Brass, J. (1999) Enterprise in higher education: changing the mindset. London: DfEE.

[5] Veciana, J.M., Aponte, M. and Urbano, D. (2005) University students' attitudes towards entrepreneurship: a two countries comparison. International Entrepreneurship and Management Journal, 1(2) 165-182.

[6] Willis, G.B. (2004) Cognitive interviewing: a tool for improving questionnaire design. Thousand Oaks, Calif: Sage Publications.d

[7] Wienclaw, R.A. (2015) Interviews. Research Starters: Sociology (Online Edition).

[8] Powell, J. (2012). A review of student enterprise and entrepreneurship at Lancaster University. Masters. Lancaster University. Available from 
http://eprints.lancs.ac.uk/76449/1/A Review of Student Enterprise and Entrepreneurship at Lanca ster University Jon Powell IEEP Submission 23.07.12.pdf [accessed 29 July 2016]

[9] Dehli, M.N. (2016) Hackathons as ground for creating start-ups: evidence from THE Port 2014. MSc. Norwegian University of Science and Technology. Available from https://cds.cern.ch/record/2156936 [accessed 28 July 2016]

[10] Lodato, T.J. and DiSalvo, C. (2016) Issue-oriented hackathons as material participation. New Media \& Society, 18(4) 539-557.

[11] Komssi, M., Pichlis, D., Raatikainen, M., Kindstrom, K. and Jarvinen, J. (2015) What are hackathons for?. IEEE Software, 32(5) 60-67.

[12] Nissenbaum, H. (2004) Hackers and the contested ontology of cyberspace. New Media \& Society, 6(2)195-217.

[13] Briscoe, G., Virani, T.E. and Dima, M. (2015) Hackathons: why co-location?. Available from https://qmro.qmul.ac.uk/xmlui/handle/123456789/6541 [accessed 28 July 2016]

[14] Briscoe, G. and Mulligan, C. (2014) Digital innovation: the hackathon phenomenon. Available from https://qmro.qmul.ac.uk/xmlui/handle/123456789/11418 [accessed 28 July 2016]

[15] Ward, D., Hahn, J. and Mestre, L. (2014) Adventure code camp: library mobile design in the backcountry. Information Technology and Libraries, 33(3) 45-52.

[16] Constine, J. (2013) British Airways launches UnGrounded 'innovation lab in the sky' to solve problems by putting techies on planes together. TechCrunch, 20 March. Available from https://techcrunch.com/2013/03/20/british-airways-ungrounded/ [accessed 28 July 2016]

[17] Marchand, J., Hermens, A. and Sood, S. (2015) Student entrepreneurship: a research agenda. International Journal of Organisation Innovation, 8(2) 266-281.

[18] Ronstadt, R. (1985) The educated entrepreneurs: a new era of entrepreneurship education is beginning. American Journal of Small Business, 10(1) 7-23.

[19] Gielnik, M.M., Frese M., Kahara-Kawuki, A., Katono, I.W., Kyejjusa, S., Ngoma, M., Munene, J., Namatovu-Dawa, R., Nansubuga, F., Orobia, L., Oyugi, J., Sejjaaka S., Sserwanga, A., Walter, T., Bischoff, K.M. and Dlugosch, T.J. (2015) Action and action-regulation in entrepreneurship: evaluating a student training for promoting entrepreneurship. Academy of Management Learning \& Education, 14(1) 69-94.

[20] Mumm, J. (2012) Rise of the hack [blog]. 16 March. Available from: http://www.tokbox.com/blog/rise-of-the-hack/ [accessed 28 July 2016] 